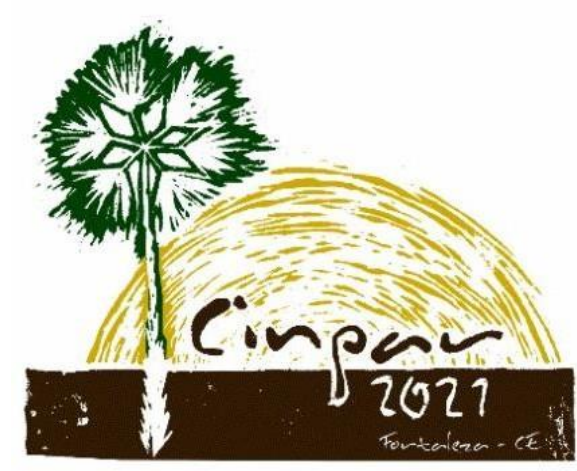

XVII Congresso Internacional sobre Patologia e Reabilitação das Construções

XVII Congreso Internacional sobre Patología y Rehabilitación de las Construcciones

XVII International Conference on Pathology and Constructions Rehabilitation

FORTALEZA (Brasil), 3 a 5 de junho de 2021 https://doi.org/10.4322/CINPAR.2021.013

\title{
Instruções para a Preparação das Comunicações ao XII congresso Internacional sobre Patologia e Reabilitação de Estruturas
}

\section{Case Study of Pathological Manifestations in a Building in Sobral - CE}

\author{
Tarcisio PARENTE ${ }^{1}$, Sandy CORDEIRO ${ }^{2}$ \\ ${ }^{1}$ Faculdade Luciano Feijão, Sobral, Ceará, tarcisiogparente@gmail.com ${ }^{1}$ \\ ${ }^{2}$ Faculdade Luciano Feijão, Sobral, Ceará, sandy pereirra@hotmail.com ${ }^{2}$
}

Resumo: Este trabalho trata da inspeção e identificação de manifestações patologicas em uma edificação, situada na cidade de Sobral/CE. Neste estudo foi efetuado uma inspeção visual com registro fotográfico, aliado a um levantamento de relatos sobre o histório de drenagem do local e sobre a existência de corpos hídricos no local. Foram localizado cinco sintomas principais das manifestações patológicas presentes no local, eflorescências, desplamento de revestimentos, desgaste do piso, trincas na alvenaria e afundamento do piso. Como possíveis causas observou-se um fluxo ascentuado de ascenção capilar e uma possível aplicação de material inadequado no aterro.

Palavras-chave: Manifestação Patológica. Recalque. Eflorescência

ABSTRACT: This work deals with the inspection and identification of pathological manifestations in the ediffication located in Sobral / CE. In this study, a visual inspection with photographic record was performed, together with a survey of the drainage history of the site and the existence of water bodies in the site. Five main symptoms of the pathological manifestations present in the site were located, efflorescences, unveiling of the coatings, floor wear, masonry cracks and floor sinking. Possible causes include increased flow of capillary rise and possible application of inappropriate material to the landfill.

Keywords: Pathological Manifestation. Settlement. Efflorescence. 


\section{Introdução}

As obras de engenharia desgastam-se com o passar dos anos e, caso não haja uma adequado planos de manutenção, podem desenvolver danos, conhecidos como manifestações patológicas, os quais podem ou não comprometer gravemente a utilização da edificação. A patologia é considerada a ciência que estuda as causas, os mecanismos, as ocorrências, manifestação e consequências de erros em edifícios civis com baixo desempenho de construção pré-estabelecido pelo usuário. As patologias ocorrem nas construções em alguns topicos, planejamento de obra, caracteristica dos materiais, execução na hora da aplicação desses materiais, projeto e entre outros.

De acordo com Azevedo (2011), patologia pode ser conceituada, segundo sua aplicação na medicina, como o ramo da ciência que investiga e diagnostica doenças, estudando sua origem, seus sintomas, os agentes causadores e os mecanismos de ocorrência. No ramo da engenharia civil, Silva et.al (2017) afirma que ele é empregado para designar deficiências e deformidades que surgem em estruturas, assim como a causa dos diversos sintomas. As patologias podem ocorrer por conta de alguns fatores, se o erro ocorreu durante a execução do projeto, houve um falha do projetista, não foi bem executado, mas quando o imprevisto acontece na qualidade do material a culpa ja passa para o fabricante, entretando se suceder na etapa da obra a falha é da execução.

Para Jonov (2013), frequentemente as edificações passam por manifestações patológicas, representando um dos grandes problemas no decorrer de sua vida útil, relacionando-se à idade da construção, ao clima, aos materiais e técnicas construtivas aplicadas e ao nível de controle de qualidade empregado. Para os edificios analisados, existem vários inidicios problematicos, como os que foram citados, as condições patológicas podem ser causadas por falta de fiscalização ou por profissionais não qualificados.

Este artigo apresenta o estudo de caso de manifestações patológicas ocorridas no Laboratório de Materiais de Construção da Universidade Estadual Vale do Acaraú (UVA), situado dentro do campus CIDAO, na cidade de Sobral/CE, o qual é utilizado para desenvolvimente de pesquisas e aulas práticas do curso de bacharelado em Engenharia Civil. Que tem como intuito enaltecer os problemas patologicos da edificação analisada, como ocoreu essa falha e qual método é utilizado para possivel correção de tal patologia. Uma vez que essa problemática possibilita danos na estetica da estrutra e uma perda de valor considerado, sendo assim ideal um estudo do caso para uma correta solução e previsão.

Por esse âmbito, esse trabalho possui uma metodologia de aspecto prático e convicto de avaliações de patologia em edificação. Ocorrendo assim, vistorias no local, identificação das manifestações patologicas. A esse repeito, depois identificado o problema, resta escolher a melhor opção para a ingerência de tal ocorrência. Logo, essa pesquisa possui pontos positivos para o conhecimento das patologias mais comuns que ocorrem na construção civil, conhecendo assim tais problemas, com isso, evita que ocorra patologias estudadas no trabalho para as construções.

\section{Objetivos}

\subsection{Objetivo Geral}

Identificar as manifestações patológicas da edificação de estudo e analisar as possíveis causas e consequencias.

\subsection{Objetivos Específico}

- Apresentar as manifestações patológicas em um edifício;

- Pesquisar o motivo no qual o surgimento das patologias;

- Enunciar alternativas para correta solução do problema. 


\section{Metodologia}

A metodologia empregada se baseou na inspeção visual das instalações, sendo realizada de forma conjunta o registro fotográfico das manifestações patológicas localizadas, tal registro ocorrido em uma edificação na cidade de Sobral-CE. Por esse âmbito, pesquisa realizada no período entre fevereiro e junho de 2020, ciclo no qual ocorria a pandemia da COVID-19, por conta disso, ocorrendo assim, interrupções em diversas áreas da construção civil. No entanto, esse fato não afetou a conclusão da pesquisa. Todavia, de posse dos problemas encontrados, foi realizada uma revisão bibliográfica sobre seus mecanismos de ocorrência. Por último, questionou-se funcionários e conhecedores da área para delimitar as possíveis causas dos sintomas observados. A esse respeito, o presente trabalho tem classifica-se como quali-quantitativo, pois ocorreu questionario com pessoas e pesquisa bibliografica. No que se trata do método de pesquisa, foi utilizado o indutivo, pois a partir da análise das patologias, infere-se as conclusões do trabalho. A exposição dos resultados obtidos e a observações perante ao tema far-se-ão nos capítulos seguintes.

\section{Fundamentação Teórica}

\subsection{Causas e Síntomas}

Olivari (2003) lembra que a maioria das manifestações patológicas podem ser vistas e por suas características classificadas, elegendo como os principais sintomas presentes nas edificações:
a. Esmagamento do Concreto;
b. Carbonatação;
c. Corrosão da Armadura;
d. Fissuras ou trincas em elementos estruturais e alvenarias;
e. Desagregação do concreto;
f. Disgregação do concreto (ruptura do concreto);

g. Percolação de água;

h. Manchas, trincas e descolamento de revestimento em fachadas;

Alerta Olivari (2003), que algumas das principais causas das manifestações patológicas são:
a. Recalque das fundações;
b. Movimentação térmica;
c. Excesso de deformação das peças estruturais;
d. Sobrecargas ou acumulo de tensões;
e. Retração do cimento;
f. Carbonatação;
g. Expansão de armadura (corrosão);
h. Reações químicas; 
Contudo, conforme Verçoza (1991), a umidade se apresenta como o principal vetor para a maioria das manifestações patológicas. Silva et al. (2017), comenta que ela é um elemento essencial para a ocorrência de eflorescências, ferrugens, mofo, bolores, perda de pinturas, de rebocos e alguns acidentes estruturais. De acordo PEREZ (1985), a umidade nas construções mostra-se como um dos problemas mais difíceis de serem corrigidos na construção civil.

Verçoza (1991) informa que uma das maneiras de ocorrência de umidade nas edificações, é por meio de ascenção capilar. Souza (2008) atribui este processo às condições de umidade do solo e à ausência de obstáculos que impeçam o progresso da água.

\subsubsection{Recalque}

Um dos tópicos de maior preocupação para a Engenharia Geotécnica, é a determinação de deformações ocasionadas na superfície de terrenos por carregamentos verticais (PINTO, 2006). O solo é relativamente mais deformável do que outros materiais empregados na construção, atingido na tensão limite de segurança uma deformação unitária de 2,5\%, enquanto os outros atingem cerca de 0,005\% (CAPUTO, 1988). 0 acréscimo de tensão no solo, causado pela construção de fundações e outros elementos, ocasiona um rebaixamento de suas camadas. Este pode ser dividida em três parcelas: recalque imediato (elástico), recalque por adensamento primário e recalque por compressão secundária. Dessa maneira, segundo Das (2014), o recalque total pode ser definido pela Equação 01:

$$
S_{T}=S_{C}+S_{S}+S_{e}
$$

Onde:

$S_{T}=$ recalque total;

$S_{C}=$ recalque primário;

$S_{S}=$ recalque secundário;

$S_{e}=$ recalque imediato.

Quando o solo é constituído por uma argila, segundo Fernandes (2016), ele possui naturalmente o teor de umidade e o índice de vazios elevados, características que, de acordo com Terzaghi, Peck e Mesri (1996), resulta em um potencial para grandes deformações volumétricas. Por outro lado, sua condutibilidade hidráulica é muito menor que a da areia, dessa maneira, o processo de drenagem e redução da poropressão ocorre gradativamente durante um longo intervalo de tempo. Fernandes (2016) reconhece que estas duas propriedades, grande compressibilidade e longo período de consolidação, desde sempre acarretam grandes dificuldades às construções.

\subsubsection{Eflorescência}

Para UEMOTO (1985), o termo eflorescência significa a formação de depósito salino na superfície de alvenarias, o que é resultado da exposição de intempéries. Souza (2008), afirma que este fenômeno ocorre devido a três fatores: sais solúveis, presença de água e pressão hidrostática. Ainda sengudo Sousa (2008), a água das chuvas, ou que se encontra no solo, satura o elemento e dissolve seus sais, sendo que, após a evaporação da água da soluções que migrou para a superfície, gera um depósito geralmente branco.

\section{Resultados}

Após a visita de inspeção realizada no local de estudo, foram identificados cinco sintomas principais. São eles:

- Aparecimento de depositos de sais;

- Desplacamento de revestimento cerâmico; 
- Desgaste da superfície doo piso;

- Rebaixamento do piso;

- Surgimento de trincas;

A Figura 01 mostra um deposito salino acima do nível do revetimento da parede.

Figura 01 - Deposito salino na parede.

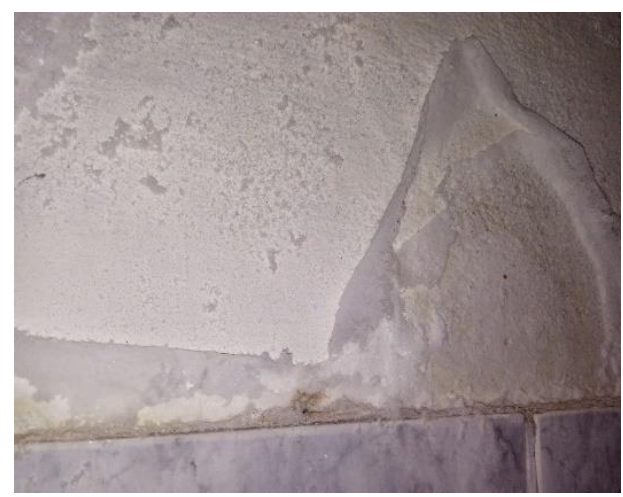

Figura 02 - Desplacamento devido deposito salino.

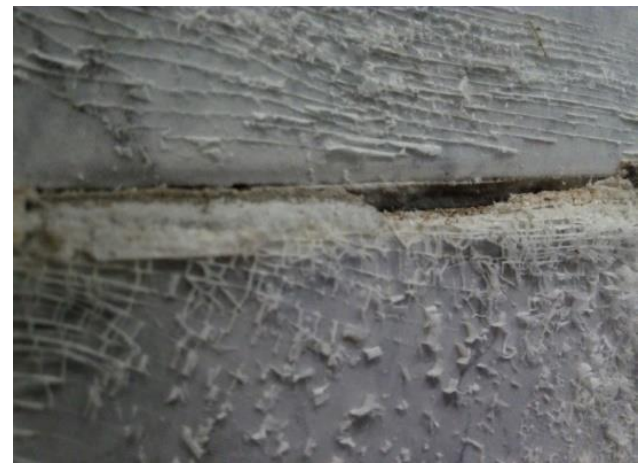

Como é possível observar nas Figura 02 e 03, que o acumulo de sais decorrentes do processo de formação da eflorecência sob o revertimento cerâmico está causando o desplacamento dos componentes.

Figura 03 - Eflorescência nas placas cerâmicas

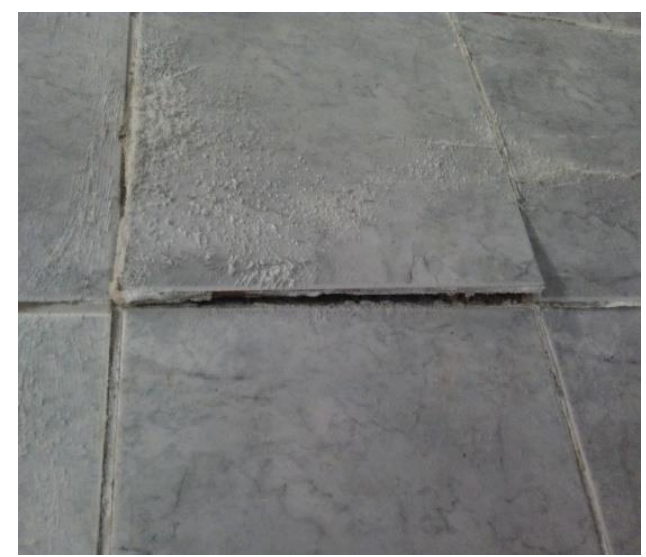

A Figura 04 e 05 apresentam, respectivamente, o desenvolvimento de um processo de eflorescência no piso e o avançado grau de abrasão ao qual ele foi submetido. 


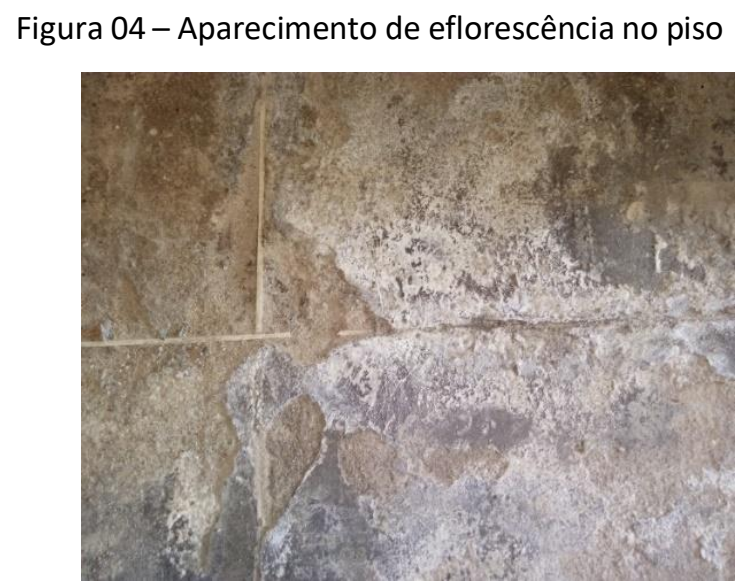

Figura 05 - Estado de desgaste do piso

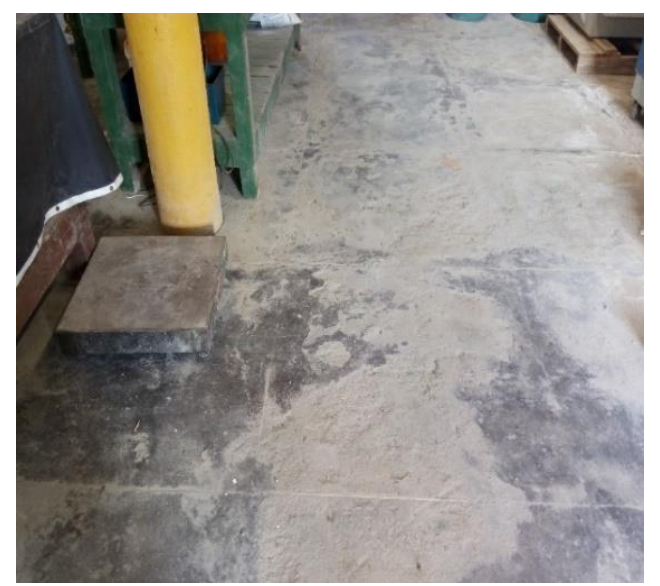

A Figura 06 mostra um ponto onde foi identificado um grande valor recalque do piso.

Figura 06 - Afundamento da piso

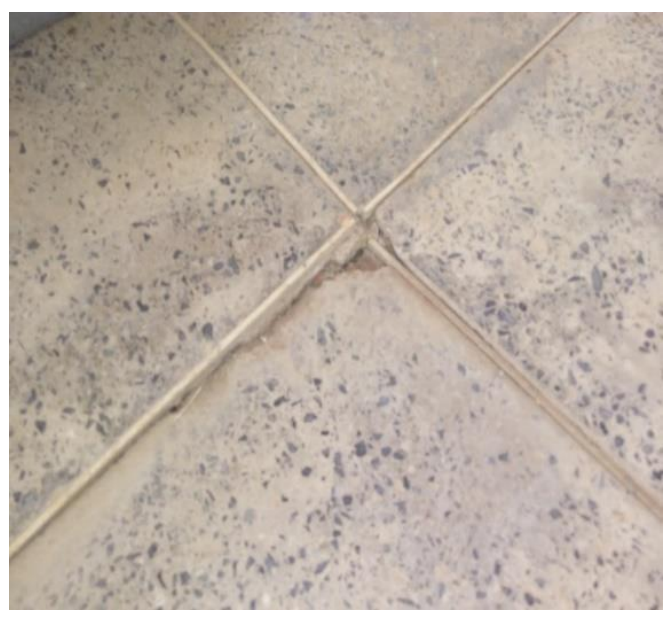

A Figura 07 apresenta o aparecimento de grandes aberturas na alvenaria interna de uma das salas das construção estudada. 


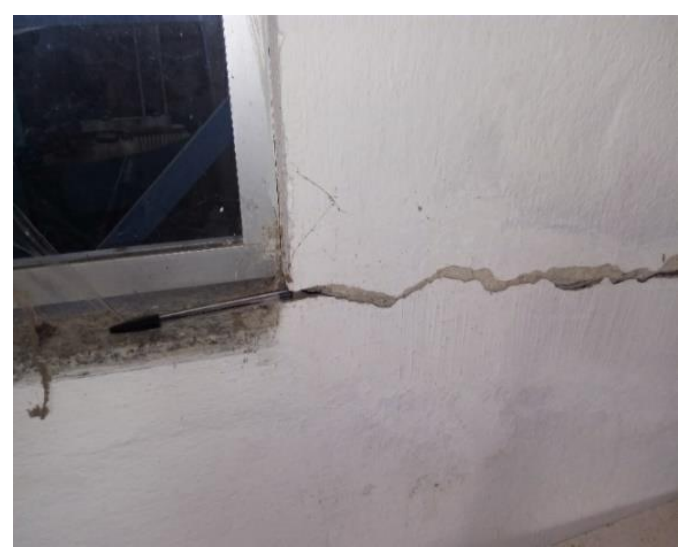

Segundo relatos, a área onde atualmente está localizada a edificação, anteriormente se tratava a de uma lagoa, a qual foi aterrada possivelmente com material inapropriado. Historicamente, em áreas de lagoas aterradas há uma convergência de água e uma pequena profundidade da superfície freática, o que propicia uma constante saturação do solo, nas épocas mais umidade do ano. Este estado de umidade do solo favorece o desenvolvimento de ascenções capilares.

\section{Conclusão}

O trabalho teve como propósito designar atraves de vistorias, as principais manifestações patologicas em uma edificação em Sobral-CE. Por esse âmbito, essa análise proposta de estudo é de necessária relevância quando planeja uma garantia de qualidade e desempenho na execução do edificio. No entanto, muitas manifestações patológicas foram encontradas no edifício, caso ocorresse uma vistoria no processo de construção, poderia ter sido evitado. Cuja inspeções é em relação à eficácia da especificação do projeto e ao controle de qualidade da obra.

Conclui-se que a presença constante de umidade sob a edificação propiciou um danoso fluxo de ascenção capilar, o que desencadeou os muitos casos de eflorescência e conseguentimente o desplacamento do revestimento cerâmico e a redução da resistência à abrasão do piso.

Do ponto de vista geotécnico, a possível utilização de material inapropriado para o aterro da construção, pode ter ocasionado um processo acentuado de recalque, o qual promoveu o rebaixamento do piso e o aparecimento de fissuras de grande estenção e abertura na alvenaria. Sugere-se então a remoção dos revetimentos danificados, a aplicação de impermeabilizantes e a execução de um novo revestimento, quanto ao recalque seria necessária uma intervenvenção no aterro a edificação e no sistema de drenagem, o que torna mais onerosa a recuperação.

Logo, a metodologia aplicada durante o trabalho foi de grande importância, pois foi a partir dela que o estudo atingiu o objetivo proposto da pesquisa. Com o intuito de prevalecer e melhorar a qualidade dos metodos de revestimento, aconselha especificar alguns modelos para certas áreas da edificação, sendo assim evitando alguns transtornos por conta da caracteristica do material.

\section{Referências Bibliográficas}

AZEVEDO. M. T. et al. Concreto: Ciência e Tecnologia. São Paulo: Ibracon, 2011. 1902p, v.2.

CAPUTO, H. P. MECÂNICA DOS SOLOS E SUAS APLICAÇÕES: Fundamentos. 6. ed. Rio de Janeiro - RJ: LTC, 1988.

DAS, B. M. Fundamentos de Engenharia Geotécnica. Tradução: Noveritis do Brasil. 8. ed. São Paulo: Cengage Learning, 2014. 
FERNANDES, M. M. MECÂNICA DOS SOLOS: conceitos e princípios fundamentais. São Paulo - SP: Oficina de Textos, 2016. v. 1.

JONOV, C; Nascimento, N; Silva, A. "Avaliação de danos às edificações causados por inundações e obtenção dos custos de recuperação. Ambiente construído", Porto Alegre, RS,Brasil ,v.13,n.1,p.75-94, jan a mar de 2013.

OLIVARI, Giorgio. Patologia em Edificações. defesa - trabalho de conclusão de curso, graduação em engenharia civil, dissertação. São Paulo: Universidade Anhembi Morumbi. 2003. 95p.

PEREZ, A. R. Umidade nas Edificações: recomendações para a prevenção de penetração de água pelas fachadas. Tecnologia de Edificações, São Paulo. Pini, IPT - Instituto de Pesquisas Tecnológicas do Estado de São Paulo, Coletânea de trabalhos da Div. de Edificações do IPT. 1988. p.571-78.

PINTO, C. S. Curso Básico de Mecânica dos Solos em 16 Aulas. 3. ed. São Paulo - SP: Oficina de Textos, 2006.

SILVA, A. L. I. et al. PATOLOGIA DAS CONSTRUÇÕES: Impermeabilidade. Revista conexão eletrônica, Três Lagoas, MS, v. 14, n. 1, p. 1776-1783, 2017.

SOUZA, M. F. PATOLOGIAS OCASIONADAS PELA UMIDADE NAS EDIFICAÇÕES. Orientador: Prof. Dr. Adriano de Paula e Silva. 2008. Monografia (Especialização) - Universidade Federal de Minas Gerais, Belo Horizonte, 2008.

TERZAGHI, K.; PECK, R. B.; MESRI, G. Soil Mechanics in Engineering Practice. 3. ed. New York - NY: John Wiley \& Sons, Inc., 1996.

UEMOTO, K. L. Patologia: Danos causados por eflorescência. Tecnologia de Edificações, São Paulo. Pini, IPT Instituto de Pesquisas Tecnológicas do Estado de São Paulo, Coletânea de trabalhos da Div. de Edificações do IPT. 1988. p.561- 64.

VERÇOZA, E. J. Patologia das Edificações. Porto Alegre, Editora Sagra, 1991.172p. 